\title{
Identifying the connective strength between model parameters and performance criteria
}

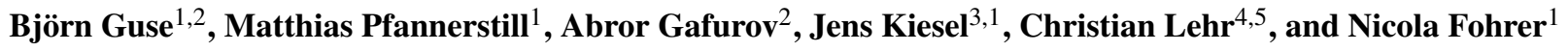 \\ ${ }^{1}$ Christian Albrechts University of Kiel, Institute of Natural Resource Conservation, Department of Hydrology and \\ Water Resources Management, Kiel, Germany \\ ${ }^{2}$ GFZ German Research Centre for Geosciences, Section 5.4 Hydrology, Potsdam, Germany \\ ${ }^{3}$ Leibniz Institute of Freshwater Ecology and Inland Fisheries (IGB), Berlin, Germany \\ ${ }^{4}$ Leibniz Centre for Agricultural Landscape Research (ZALF), Institute of Landscape Hydrology, Müncheberg, Germany \\ ${ }^{5}$ University of Potsdam, Institute for Earth and Environmental Sciences, Potsdam, Germany
}

Correspondence to: Björn Guse (bguse@hydrology.uni-kiel.de)

Received: 24 January 2017 - Discussion started: 1 February 2017

Revised: 15 September 2017 - Accepted: 19 September 2017 - Published: 15 November 2017

\begin{abstract}
In hydrological models, parameters are used to represent the time-invariant characteristics of catchments and to capture different aspects of hydrological response. Hence, model parameters need to be identified based on their role in controlling the hydrological behaviour. For the identification of meaningful parameter values, multiple and complementary performance criteria are used that compare modelled and measured discharge time series. The reliability of the identification of hydrologically meaningful model parameter values depends on how distinctly a model parameter can be assigned to one of the performance criteria.

To investigate this, we introduce the new concept of connective strength between model parameters and performance criteria. The connective strength assesses the intensity in the interrelationship between model parameters and performance criteria in a bijective way. In our analysis of connective strength, model simulations are carried out based on a latin hypercube sampling. Ten performance criteria including Nash-Sutcliffe efficiency (NSE), Kling-Gupta efficiency (KGE) and its three components (alpha, beta and r) as well as RSR (the ratio of the root mean square error to the standard deviation) for different segments of the flow duration curve (FDC) are calculated.

With a joint analysis of two regression tree (RT) approaches, we derive how a model parameter is connected to different performance criteria. At first, RTs are constructed using each performance criterion as the target variable to detect the most relevant model parameters for each perfor-
\end{abstract}

mance criterion. Secondly, RTs are constructed using each parameter as the target variable to detect which performance criteria are impacted by changes in the values of one distinct model parameter. Based on this, appropriate performance criteria are identified for each model parameter.

In this study, a high bijective connective strength between model parameters and performance criteria is found for lowand mid-flow conditions. Moreover, the RT analyses emphasise the benefit of an individual analysis of the three components of KGE and of the FDC segments. Furthermore, the RT analyses highlight under which conditions these performance criteria provide insights into precise parameter identification. Our results show that separate performance criteria are required to identify dominant parameters on low- and mid-flow conditions, whilst the number of required performance criteria for high flows increases with increasing process complexity in the catchment. Overall, the analysis of the connective strength between model parameters and performance criteria using RTs contribute to a more realistic handling of parameters and performance criteria in hydrological modelling.

\section{Introduction}

In rainfall-runoff models, hydrological processes are represented in a simplified way. Fluxes and changes in states are described by mathematical equations. To adapt the model to the hydrological conditions of the study catchments, multiple 
parameters are included in the model structure. Each of them has a specific role representing one or multiple processes.

For hydrologically reliable model simulations, it is required to identify parameter values that lead to a reasonable reproduction of their corresponding hydrological processes (Wagener et al., 2003; Pfannerstill et al., 2015). Typically, model parameters are identified using performance criteria which minimise the differences between measured and modelled discharge. In this context, we use "performance criteria" as an overall term both for statistical performance metrics and signature measures.

It is assumed that a performance criterion contributes to a better interpretation of the hydrological behaviour if it is related directly to the corresponding components of the model structure and controlled by the selected model parameter (Yilmaz et al., 2008; Gupta et al., 2009; Martinez and Gupta, 2010; Pechlivanidis et al., 2014). Thus, it is important to establish a strong relationship between a model parameter and a performance criterion which is appropriate for the associated process (Fenicia et al., 2007). An appropriate set of performance criteria should be selected so that all relevant hydrological conditions in a catchment are represented by at least one performance criterion. However, the selection of the most appropriate performance criteria for precise parameter identification is still a challenge. To investigate this, the interrelationship between model parameters and performance criteria needs to be identified as an initial step towards accurate parameter identification.

In this context, the relevance of model parameters is sitespecific depending on the prevailing dominant processes (Gupta et al., 2014; Guse et al., 2016). The number and type of performance criteria which are required to explain the hydrological behaviour in a study catchment is unclear and depends on catchment characteristics and its underlying process complexity (Wagener and Montanari, 2011; Pokhrel et al., 2012).

To ensure a hydrologically reliable parameter identification, it is currently commonly agreed that multiple and contrasting performance criteria are required to determine whether parameters are only relevant specifically for a certain performance criterion (Gupta et al., 1998, 2009; Vrugt et al., 2003; Krause et al., 2005; Reusser et al., 2009; Guse et al., 2014). Each performance criterion emphasises different hydrological conditions with respect to, for example, discharge dynamics, discharge magnitude, water balance, or high or low flows (Madsen, 2000; Boyle et al., 2001; Wagener et al., 2001). By selecting a specific performance criterion, a certain part of the hydrograph is inevitably weighted higher than other parts and thus, different parts of the hydrograph are emphasised or neglected during parameter identification (Gupta et al., 1998; Yapo et al., 1998; Pokhrel et al., 2012; Pechlivanidis et al., 2014; Pfannerstill et al., 2014b; Haas et al., 2016).

In order to capture magnitude and dynamic in the modelled discharge time series, a combination of statistical performance metrics and signature measures in the model evaluation is recommended (van Werkhoven et al., 2008, 2009; Pfannerstill et al., 2014b). Typical statistical performance metrics are the Nash-Sutcliffe efficiency (NSE) (Nash and Sutcliffe, 1970) and the Kling-Gupta efficiency (KGE) (Gupta et al., 2009; Kling et al., 2012), which separately considers the three components bias (KGE_beta), variability (KGE_alpha) and correlation (KGE_r) to improve the estimation of the performance error compared to the NSE. Signature measures are directly related to catchment functions with the aim to consider the relevance of a certain hydrological component individually (Yilmaz et al., 2008; van Werkhoven et al., 2009; Pokhrel et al., 2012). Signature measures based on flow duration curves (FDC) provide diagnostic information of how a model performs for different discharge magnitudes (Yilmaz et al., 2008; Cheng et al., 2012; Yaeger et al., 2012; Pfannerstill et al., 2014b). Pfannerstill et al. (2014b) showed that a separation of the flow duration curve into five segments improved the model results for different discharge magnitudes and reduced the trade-off between satisfying results both for high and low flows in the same model run. By using different signature measures, the hydrologic behaviour is represented better in the performance assessment (Martinez and Gupta, 2011; Singh et al., 2011; Euser et al., 2013) and precise interpretation of the accuracy in reproducing hydrological components is achieved.

The relevance of model parameters for a performance criterion can be derived using sensitivity analyses. In addition to using model results directly for a sensitivity analysis (Reusser et al., 2011; Guse et al., 2014), performance criteria could be used to detect the most relevant model parameters. Several studies have shown that the relevance of model parameters changes if different performance criteria are used (van Werkhoven et al., 2008; Abebe et al., 2010; Herman et al., 2013). Gupta et al. (2009) emphasised the need to investigate how changes in model parameter values influence the three components of the Kling-Gupta efficiency (KGE).

Given the variety of performance criteria and the related amount of possible relationships between model parameters and performance criteria, Gupta et al. $(2008,2009)$ argue that a better understanding of the interrelationship between model parameters and performance criteria should be a core idea of diagnostic model analysis. To our knowledge, the relationship of model parameter and performance criteria has only been analysed up to now in one direction, namely from model parameters to model outputs and performance criteria. Thus, the opposite direction which is the suitability of a certain performance criterion to identify a certain model parameter, which can be directly used to improve the representation of the corresponding hydrological component in the model, remains so far unconsidered and is still a challenging task.

To investigate the interrelationship between performance criteria and model parameters in a bidirectional manner, we built on the approach of Singh et al. (2014a) and Pechlivanidis and Arheimer (2015), who used classification and regres- 
sion trees (CART) to classify performance criteria with respect to their appropriateness for different catchment characteristics. Both studies showed how different catchment characteristics and derived signatures resulted in a typical model performance. We adapted this idea to the relationship between performance criteria and model parameters and suggest an innovative concept of bijective connective strength between model parameters and performance criteria with the aim to improve the parameter identification.

The connective strength assesses how strongly model parameters and performance criteria are interrelated using regression trees (RTs). (1) We investigate how the most influencing parameters vary for the selected performance criteria to analyse how strongly a set of model parameters affects different performance criteria. (2) Looking from the side of the model parameters, we analyse which performance criteria are impacted by changes in a certain model parameter. In this way, performance criteria are detected which are able to represent changes in a certain parameter. A high connective strength is given in the case where (1) a performance criterion is controlled by one model parameter and (2) this model parameter influences the same performance criterion to a relevant extent.

With this study, we present a way to detect the appropriateness of performance criteria that are most helpful in the identification of hydrologically sound model parameter values. We analyse how performance criteria are controlled by different model parameters by using regression trees, how selective model parameters and performance criteria are related and how this relationship changes for different types of performance criteria.

\section{Methods and materials}

\subsection{Study catchments}

In contrasting catchments, different hydrological processes are of major relevance (Atkinson et al., 2002; Merz and Blöschl, 2004; Jothityangkoon and Sivapalan, 2009; Guse et al., 2016) and thus also the ability of a certain performance criterion in identifying a certain model parameter varies. With increasing relevance of a process, an accurate reproduction in the model becomes more important. Therefore, two catchments with different catchment characteristics were selected in this study to check the applicability of the proposed approach (Fig. 1). For the analysis, measured daily discharge time series from their catchment outlets were used to assess model performance.

\subsubsection{Treene}

The Treene catchment (up to the hydrological station Treia, $481 \mathrm{~km}^{2}$ ), located in northern Germany is a typical lowland catchment with strong groundwater dominance of total discharge even under high-flow conditions (Guse et al., 2014;
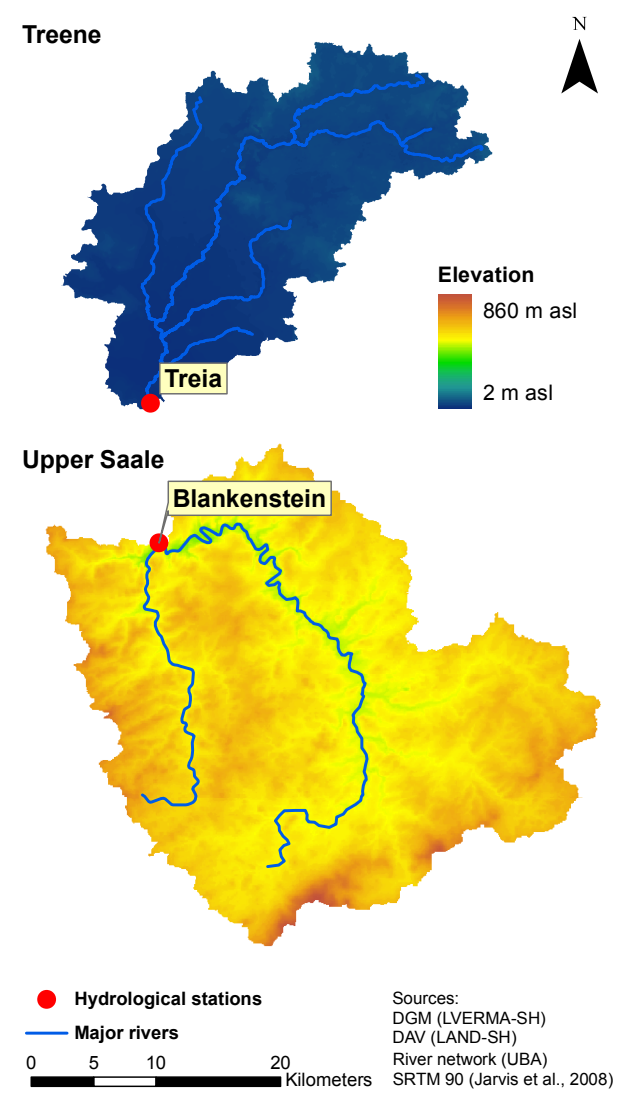

Figure 1. Two study catchments (Treene and Saale) and their catchment elevation. The same elevation legend is used for both catchments.

Pfannerstill et al., 2015; Guse et al., 2016). Moreover, tile flow is a relevant process since large parts of its agriculture area are drained (Kiesel et al., 2010). Other fast runoff components are of minor relevance as expected from the low topographic gradient in the catchment (maximum elevation of $80 \mathrm{~m}$ ). The Treene catchment is dominated by agricultural areas whilst only a minor part is covered by forests and urban areas (Guse et al., 2015). Mean annual precipitation is about $995 \mathrm{~mm} \mathrm{a}^{-1}$ with the highest values in summer months and monthly average temperature ranges from $1.5^{\circ} \mathrm{C}$ (January) to $17.6^{\circ} \mathrm{C}$ (July) with an average annual temperature of $9.2^{\circ} \mathrm{C}$. Mean discharge at the catchment outlet is $6.23 \mathrm{~m}^{3} \mathrm{~s}^{-1}$.

\subsubsection{Upper Saale}

The Upper Saale catchment (hydrological station Blankenstein, $1013 \mathrm{~km}^{2}$ ) is located in mid-range mountains in southeast Germany. This catchment is characterised by a higher diversity in dominant processes compared to the Treene catchment, with temporal changes in the relevance of snowmelt, surface runoff and groundwater flow (Guse et al., 2016). The landscape is covered mostly by forest (upper parts) and agricultural fields (lower parts). Contrary to the Treene catch- 
ment, the altitude in the Upper Saale catchment is higher (between 415 and $856 \mathrm{~m}$ ) and slopes are steeper. Thus, fast runoff components are of higher relevance in this catchment. Mean annual precipitation is $929 \mathrm{~mm} \mathrm{a}^{-1}$ and monthly average temperature ranges from $-1.7^{\circ} \mathrm{C}$ (January) to $17.2^{\circ} \mathrm{C}$ (July) with an annual mean temperature of $7.9^{\circ} \mathrm{C}$. Mean discharge at the catchment outlet is $13.04 \mathrm{~m}^{3} \mathrm{~s}^{-1}$.

\subsection{Soil and Water Assessment Tool (SWAT)}

The conceptual and process-based eco-hydrological model SWAT (Soil and Water Assessment Tool; Arnold et al., 1998) is used in this study. The SWAT model is spatially discretised into subbasins which are subdivided into hydrological response units (HRUs) based on unique underlying information on land use, soil and slope. All water balance computations are conducted with daily temporal resolution at the scale of individual HRUs as the central calculation unit. The change in soil water storage is influenced by inputs (e.g. precipitation) and outputs (e.g. evapotranspiration, runoff components).

In this study, the SWAT3S version (Pfannerstill et al., 2014a), which is a modification of the SWAT model, was used. In SWAT3S, the groundwater modelling has been improved by subdividing the active aquifer contributing to river discharge into a fast and a slow responding one. Different runoff components (surface runoff, lateral flow, groundwater flow) are separately computed for each HRU and summarised as water yield of a subbasin. A detailed description of the SWAT model set-up for both catchments is described in Guse et al. (2016).

To analyse the relationship of performance criteria to model parameters, 12 SWAT model parameters from different hydrological components which control different parts of the hydrograph are selected in this study (Table 1). The final selection is based on studies with successful applications of the SWAT model within the studied catchments (Guse et al., 2016; Pfannerstill et al., 2015). Thus, parameter ranges were constrained according to authors' previous knowledge with the aim of reducing unrealistic parameter combinations which may lead to physically implausible process description.

Within the set of 12 parameters, 2 snow parameters regulate snowfall and snowmelt. Infiltration and surface runoff are captured by $\mathrm{CN} 2$ which is included in the curve number approach (SCS, 1972). The timing of different runoff components within the land phase is represented by lag time parameters (SURLAG, LATTIME, GDRAIN). Three soil parameters were included. For each soil layer, available water capacity (SOL_AWC) and saturated hydraulic conductivity (SOL_K) can be differentiated. The contribution of soil water from different soil depth for evaporation is regulated by a nonlinear function which is parameterised by ESCO. The groundwater module is parameterised with a retention time from soil to groundwater (GW_DELAYfsh), a partitioning coefficient between the two aquifers (RCHRGssh) and the baseflow recession factor (ALPHA_BFssh).

Based on the physically meaningful selection of these 12 model parameters, their values were varied within a set of model simulations. The intention of these model simulations was to derive the interrelationship between model parameters and performance criteria. For this, model simulations for the period from 2000 to 2010 were carried out based on 2000 different parameter sets that were generated with the latin hypercube sampling approach as implemented in the R package FME (Soetaert and Petzoldt, 2010). In the latin hypercube sampling, all model parameters were changed simultaneously within the whole parameter space. For a more detailed description, readers are referred to Pfannerstill et al. (2014b).

All parameters values were already in a hydrologically plausible range according to prior modelling experience with the study sites. These constrained parameter ranges allowed for selecting an efficient but appropriate number of simulations to perform our analyses. Please note that the intention of the presented study was not to identify the parameter values exactly, which allowed us to keep the sampling of the parameter space relatively sparse. Instead, we aimed to test and suggest the new connective strength approach. For this purpose, the number of 2000 model runs ensured a sufficient number of combinations at each node of the RTs.

\subsection{Performance criteria}

Ten performance criteria including five performance metrics and five signature measures were selected to capture different aspects of hydrological behaviour in models and as it was recommended in recent diagnostic model studies (Kling et al., 2012; Pechlivanidis et al., 2014; Pfannerstill et al., 2014b; Haas et al., 2016)

Nash-Sutcliffe efficiency (NSE) criterion (Eq. 1) is one of the most often used performance criteria in hydrology (Nash and Sutcliffe, 1970). NSE focuses on variability in measured discharge time series. It is known to give higher weights to high flows than to low flows (Schaefli and Gupta, 2007; Gupta et al., 2009; Pfannerstill et al., 2014b).

$$
\mathrm{NSE}=1-\frac{\sum_{i=1}^{N}\left(Q_{o}-Q_{s}\right)^{2}}{\sum_{i=1}^{N}\left(Q_{o}-\overline{Q_{o}}\right)^{2}},
$$

where $Q_{o}$ is measured discharge, $Q_{s}$ modelled discharge and $\overline{Q_{o}}$ mean of measured discharge.

Kling-Gupta efficiency (KGE) criteria (Gupta et al., 2009; Kling et al., 2012) is based on a decomposition of NSE into its three components (Eq. 2), which can be separately considered for each model run. Thus, model errors can be directly related to variability (KGE_alpha), bias (KGE_beta) and correlation (KGE_r) between measured and modelled discharge 
Table 1. List of SWAT models parameters. Lower and upper ranges are given as absolute range ( $r$ ), additive $(a)$ or multiplicative $(m)$ value. Further information can be found in the theoretical documentation of the SWAT model (Neitsch et al., 2011).

\begin{tabular}{|c|c|c|c|c|c|c|}
\hline Parameter name & Abbreviation & Process & Units & $\begin{array}{l}\text { Range } \\
\text { type }\end{array}$ & $\begin{array}{c}\text { Lower } \\
\text { range }\end{array}$ & $\begin{array}{l}\text { Upper } \\
\text { range }\end{array}$ \\
\hline Snow fall temperature & SFTMP & Snow & ${ }^{\circ} \mathrm{C}$ & $r$ & -2.5 & 2.5 \\
\hline Snow melt temperature & SMTMP & Snow & ${ }^{\circ} \mathrm{C}$ & $r$ & -2.5 & 2.5 \\
\hline Curve number & $\mathrm{CN} 2$ & Surface runoff & & $a$ & -10 & 10 \\
\hline Surface runoff lag time & SURLAG & Surface runoff & & $r$ & 0.8 & 4 \\
\hline Lateral flow lag time & LATTIME & Lateral flow & days & $r$ & 0.2 & 8 \\
\hline Tile flow lag time & GDRAIN & Tile flow & hours & $m$ & 0.5 & 1.5 \\
\hline Available water capacity of a soil layer & SOL_AWC & Soil water & $\mathrm{mm} \mathrm{H}_{2} \mathrm{O} \mathrm{mm} \mathrm{soil}{ }^{-1}$ & $a$ & -0.02 & 0.1 \\
\hline Saturated hydraulic conductivity of a soil layer & SOL_K & Soil water & $\mathrm{mm} \mathrm{h}^{-1}$ & $m$ & 0.5 & 3 \\
\hline Soil evaporation compensation factor & ESCO & Evapotranspiration & & $r$ & 0.2 & 1 \\
\hline Groundwater delay time (fast aquifer) & GW_DELAYfsh & Groundwater & days & $r$ & 1 & 50 \\
\hline Aquifer fraction coefficient (slow aquifer) & RCHRGssh & Groundwater & & $r$ & 0.2 & 0.8 \\
\hline Baseflow alpha factor (slow aquifer) & ALPHA_BFssh & Groundwater & $1 /$ days & $r$ & 0.001 & 0.2 \\
\hline
\end{tabular}

time series. KGE_alpha is the variability ratio between the standard deviation of modelled $\left(\sigma_{s}\right)$ and measured $\left(\sigma_{o}\right)$ discharge values. KGE_alpha larger than 1 shows that variability in modelled discharge time series is higher than in measured discharge time series, while KGE_alpha lower than 1 represents the opposite case. KGE_beta is the bias ratio between average values for modelled $\left(\mu_{s}\right)$ and measured $\left(\mu_{o}\right)$ discharge. KGE_beta larger than 1 represents an overestimation of discharge, i.e. a positive bias, while values lower than 1 illustrate an underestimation. KGE_beta and KGE_alpha represent the reproduction of the first and the second moments, respectively, as emphasised by Kling et al. (2012). KGE_r represents the correlation coefficient according to Pearson. KGE_r is used to analyse the agreement in temporal dynamics between measured and modelled discharge time series. To calculate KGE, the Euclidean distance to the ideal point in the 3-D criteria space which is created by its three components is calculated (Gupta et al., 2009). All three KGE components as well as KGE have an ideal value of one.

$$
\begin{aligned}
& \mathrm{KGE}= \\
& \quad 1-\sqrt{\left(\mathrm{KGE} \_ \text {alpha }-1\right)^{2}+\left(\mathrm{KGE} \_ \text {beta }-1\right)^{2}+\left(\mathrm{KGE} \_\mathrm{r}-1\right)^{2}} \\
& \mathrm{KGE} \_ \text {alpha }=\sigma_{s} / \sigma_{o} \\
& \text { KGE_beta }=\mu_{s} / \mu_{o} \\
& \text { KGE_r }=\text { correlation coefficient }
\end{aligned}
$$

In addition to these five performance metrics, five signature measures are selected based on FDC. The FDC only considers the discharge magnitude without considering the temporal occurrence of discharge values (Vogel and Fennessey, 1996; Yilmaz et al., 2008; Westerberg et al., 2011). To evaluate the model performance, the FDC is subdivided into five FDC segments (very high, 0-5\% days of exceedance; high, 5-20\%; medium, 20-70\%; low, 70-95\%; very low, 95-100\%) as proposed by Pfannerstill et al. (2014b) and evaluated separately. FDC signatures consider that different discharge magnitudes are controlled by different processes. Whilst the high-flow segment is mainly impacted by precipitation and fast runoff components, low flows are controlled by evapotranspiration and deep groundwater storages (Yilmaz et al., 2008; Cheng et al., 2012; Pokhrel et al., 2012; Yaeger et al., 2012; Guse et al., 2016)

For the evaluation of each FDC segment, the RSR, the ratio of the root mean square error to the standard deviation, was calculated for each FDC segment (Eq. 3) (Moriasi et al., 2007), which allows fair comparison between different segments (Haas et al., 2016). The optimal value for RSR is 0 . Using these five signature measures, the relation of model parameters to different discharge magnitudes can be derived (Pfannerstill et al., 2014b; Guse et al., 2016).

$$
\mathrm{RSR}=\frac{\sqrt{\frac{1}{N} \sum_{i=1}^{N}\left(Q_{o}-Q_{s}\right)^{2}}}{\sqrt{\frac{1}{N} \sum_{i=1}^{N}\left(Q_{o}-\overline{Q_{o}}\right)^{2}}}
$$

These 10 different performance criteria were calculated for all 2000 simulation runs. Both parameter sets and calculated performance criteria from these simulations were then used for the following analyses.

To analyse the relationship among different performance criteria the correlation coefficients between all pairwise combinations were computed. This correlation analysis enables the detection of (dis-)similarities between performance criteria. (Dis-)similarities in performance criteria as indicated by a linear relationship in the dotty plots shows that these performance criteria (do not) capture a similar type of model error for this catchment. The intention here is to detect whether each performance criterion provides additional information of model error and whether such a hypothesis is valid for both catchments with different characteristics. 


\subsection{Regression trees}

Regression trees (RTs) are a method used to order the relationship between several explaining variables and a single target variable (Breiman et al., 1984). It is a binary algorithm based on logical expressions. In a sequence of regressions, the explaining variable is subsequently determined from a set of variables that has the highest predictive value for the target variable being analysed. At each node of a regression tree, the (sub)set of model simulations is subdivided into two subsets based on a threshold value for one of the explaining variables (Singh et al., 2014a, b). All simulations with a value in the explaining variable above the threshold belong to the one group, and those with a value below the threshold to the other group. For each node, this approach is repeated until no further subdivision of a variable at a certain node explains the target variable.

The sequence of decisions is visualised in a tree diagram to detect the importance of different explaining variables for the target variable. A regression tree consists of multiple branches. Either a different or an already chosen explaining variable is selected in the next branch of the tree. The complexity of the tree reflects the complexity of the relationship between explaining and target variables.

The earlier a variable is used in the construction of an RT, the higher its importance is. The variable used in the first split has thus the maximum importance. The gain in information is maximised by defining clearly separated subgroups of the whole simulation set (Singh et al., 2014b).

For our analyses, we used the R package rpart (Therneau et al., 2015). In the rpart package, the contribution of each explaining variable on changes in the target variable is calculated. The variable importance describes how the prediction is reduced when removing this explaining variable. Thus, it summarises the contribution of the explaining variables in all nodes in explaining the changes in the target variable.

Thus, it is considered both that the explaining variable can be the most important one (and thus defines the subdivision of the subset) and that a variable has lower explanation power than the primary variable and is thus not shown in the trees. Thus, explaining variables that are not shown in the tree can also have a relevant value of variable importance. The percentage contribution of each explaining variable shows its importance for the target variable (Singh et al., 2014b).

\subsubsection{Regression trees using performance criteria as target variables (RTperf)}

RTs are applied in this study in two approaches using 2000 model simulations with pre-selected model parameters and calculated performance criterion. In our case, the set of 2000 parameter sets and performance criteria are large enough to ensure a sufficient number of combinations at each node of RT. In the first application the selected 10 performance criteria are used consecutively as target variables to construct regression trees for each performance criterion (named RTperf). As explaining variables, model parameters are used to detect which of them lead to changes in a performance criterion. The relevance of each model parameter is derived from regression trees by calculating the percentage contribution of each model parameter in explaining the variability in a performance criterion. This leads to identification of the most relevant model parameters for each performance criterion.

\subsubsection{Regression trees using model parameters as target variables (RTpar)}

Furthermore, we aim to detect more than the most relevant parameters for a certain performance criterion. Thus, in the second application, the importance of performance criteria which are most strongly impacted by changes in the value of a certain parameter is identified. This cannot be derived from RTperf. To achieve this, a bijective approach is required by looking from the point of model parameters.

Thus, this step was initialised in the opposite way to RTperf to analyse how changes in model parameters influence performance criteria. To achieve this, explaining and target variables in RT are permuted. Each model parameter is used as the target variable in RT and all performance criteria as explaining variables (named RTpar). In RTpar model parameters are analysed individually. Similarly to RTperf, the percentage contribution of each performance criterion is calculated to explain the impact of changes in values of a certain model parameter.

\subsubsection{Connective strength by comparing both regression tree approaches}

A core advantage of RT is that subsets of simulation runs are constructed in a structured way. By subdividing the simulation set based on the major influencing variables at each branch, two distinct subsets occur which differ with respect to values of model parameters as well as with respect to performance criteria. With this subset construction, the model parameter or performance criteria which has the highest explanatory power in an RT branch can be detected. This allows for a bijective analysis of the relationship between model parameters and performance criteria.

In addition to RTperf and RTpar, the percentage contributions as derived from both RT approaches are compared to analyse the connective strength between model parameters and performance criteria. Thus, four cases of connective strength for each pair of model parameter and performance criterion can be differentiated (Fig. 2).

1. High percentage contributions in both RTs (RTperf, RTpar): similar results of high percentage contributions in both RTs indicate a high bijective relationship between model parameter and performance criterion. In this case, the model parameter is clearly identifiable by using the selected performance criterion. This is the 

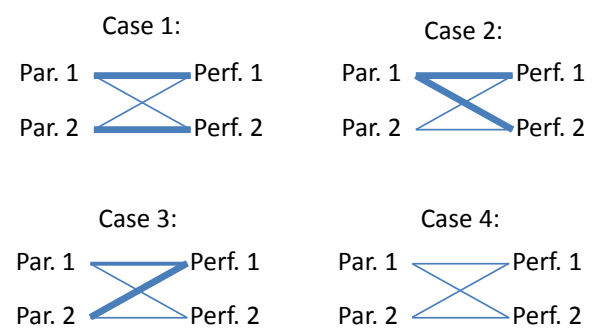

Figure 2. Chart of four cases of connective strength between model parameters and performance measures. A thicker blue line shows a higher impact of the model parameter on the performance criteria

optimal case representing a high connective strength and occurs if a certain parameter influences one performance criterion to a large extent without influencing other performance criteria significantly.

2. High percentage contribution in RTperf, but low in RTpar: in this case, a certain model parameter controls the selected performance criterion. However, this model parameter also influences other performance criteria. This case occurs if the corresponding hydrological component is very dominant and influences multiple performance criteria. Here, the connective strength cannot be fully understood when using performance criteria as target variables. From the side of the model parameter, further investigation is required regarding which performance criterion is most appropriate for parameter identification.

3. Low percentage contribution in RTperf, but high in RTpar: in this case, the model parameter is not the major controlling parameter on the selected performance criterion as detected in RTperf. However, its impact on other performance criteria is even lower which results in a high value in RTpar. Thus, the selected performance criterion is appropriate to explain the impact of changes in this model parameter, but the performance criterion is even more strongly impacted by other model parameters. This case occurs if the corresponding hydrological component is of minor relevance in describing the hydrological system of the catchment. Thus, due to its low relevance, the connective strength is also low and a parameter identification is not precise.

4. Low percentage contributions in both RTs: in this case, this model parameter does not impact the performance criterion to a relevant extent, nor is the performance criterion impacted by changes in the parameter. Thus, the connective strength is low. This parameter is not identifiable due to low relevance of the corresponding hydrological component and no distinct relationship with one of the performance criteria.
By applying this approach in two catchments with different characteristics, we analyse how strongly a certain performance criterion is connected to a specific model parameter and how this connective strength depends on the relevance of the corresponding hydrological component.

\section{Results}

\subsection{Correlation between performance criteria}

In order to understand similarities of performance criteria, pairwise correlation analysis of all performance criteria is carried out separately for each catchment. In the Treene catchment (Fig. 3, upper panel), NSE, KGE and RSR of very high and high segments of FDC are strongly correlated. Moreover, RSR of low and very low flows are highly correlated. KGE is mainly controlled by its variability component (KGE_alpha) meaning that good performance of KGE_alpha (optimum $=1$ ) also results in high performance in KGE. KGE_beta (bias component) is correlated with the middle segment of FDC. Concerning values of the performance criteria, KGE_alpha and KGE_beta are mostly higher than one, indicating an overestimation and higher variability in modelled discharge than in the measured one. Good performance in a certain segment of FDC occurs in the case of good performance in the adjacent segment(s). In the case of good performance for low flows, very low flows also perform well. Similarly, good performance for very high flows was also detected in model runs with good performance in high flows. However, correlations between RSR of (very) high and (very) low flows are lower which indicates that there are less model runs with good performance in both high and low flows.

In the Saale catchment (Fig. 3, lower panel), correlations are overall lower. The strongest correlation is observed between NSE and KGE_r. KGE is correlated to KGE_alpha and KGE_r. Thus, both variability and correlation in modelled discharge time series are relevant for good performance of KGE. KGE_beta in contrast, which is balanced between overestimation and underestimation, is of lower relevance. The correlation among signatures of FDC segments is lower compared to the Treene catchment, even between adjacent segments. Here, good performance of low flows does not result in good performance of very low flows. Worse performance of KGE_alpha (higher or lower than one) leads to a decrease in KGE since it increases the Euclidean distance of the three KGE components. However, as shown in Fig. 3, a different result was obtained between KGE_alpha and NSE. KGE_alpha larger than 1 indicates that variability is higher in modelled discharge time series which leads to a strong reduction of NSE. In contrast, lower variability in modelled rather than in measured discharge time series $($ KGE_alpha $<1)$ only results in a small reduction of NSE. This corresponds with the calculation of NSE which strongly emphasises variability in measured time series. 


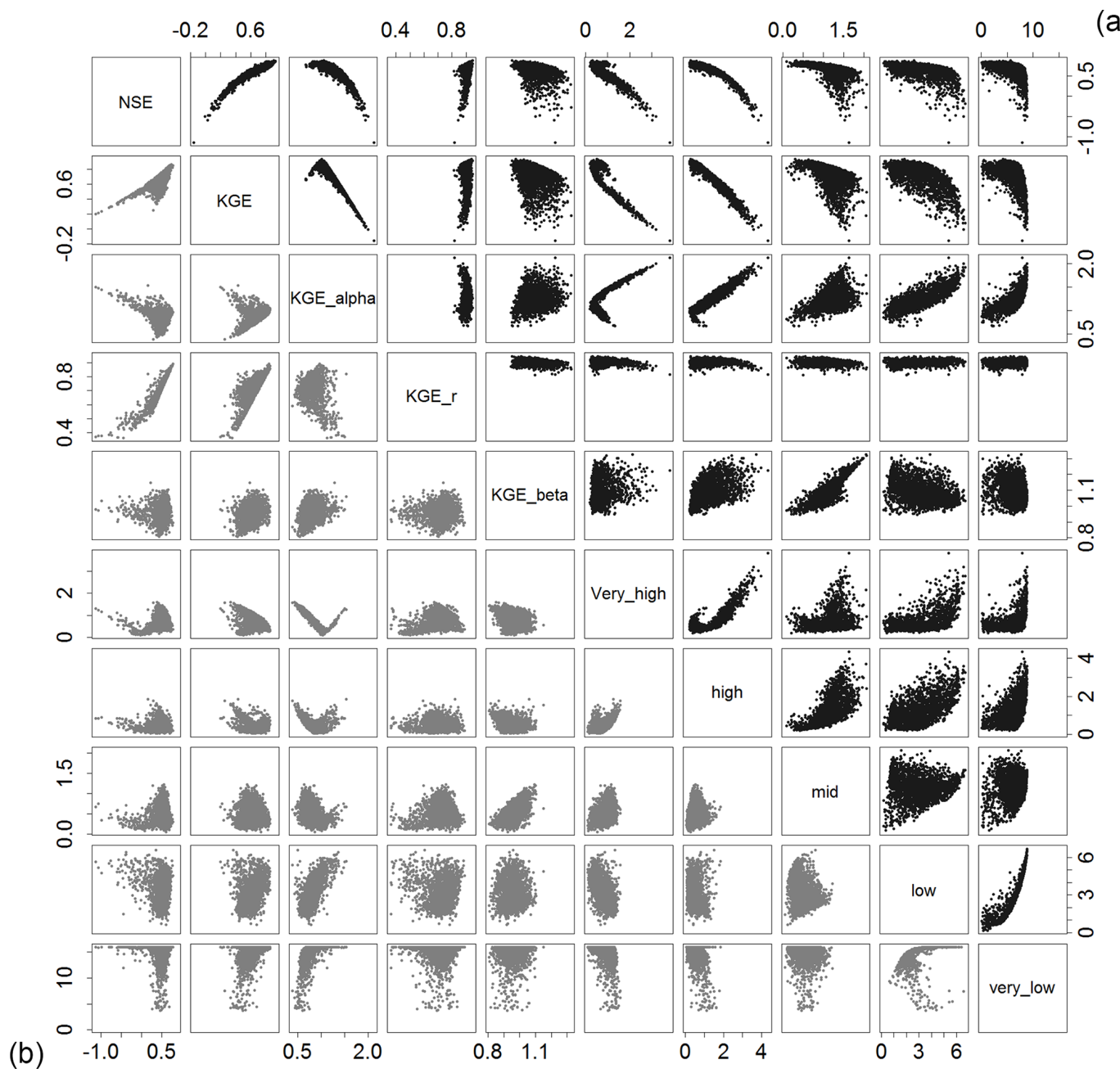

Figure 3. Scatter plot matrix of performance criteria of Treene (in black, a) and Saale (in grey, b) catchment showing pairwise performance criteria plots for 2000 model simulations. The scales on the sides show values of the respective performance criterion.

\subsection{Impact of model parameters on performance criteria (RTperf)}

The connective strength between model parameters and performance criteria was investigated using regression trees (RTs). At first, RTs were constructed using the 10 performance criteria (RTperf) as target variables. The aim of this step was to detect which model parameter most strongly affects a certain performance criterion.

Figure 4 shows the regression tree for KGE for the Treene catchment exemplarily for RTperf. Looking from top down, the most influencing model parameters for KGE are provided. The first branch is defined by groundwater retention time of the first aquifer (GW_DELAYfsh) and the second one on the right side again by GW_DELAYfsh and on the left side by the aquifer partitioning coefficient (RCHRGssh). In total, only groundwater parameters affect KGE to a relevant extent. When going along the right side of the branch, parameter settings of the controlling model parameter at these nodes are identified which lead to the best KGE on average (0.83).

To assess the connective strength between model parameters and performance criteria, the percentage contribution of model parameters as explaining variables for each performance criterion is shown for both catchments (Fig. 5). The parameter contribution in the Treene catchment to explain variability in performance criteria can be classified into three groups (Fig. 5). At first, six performance criteria are mainly influenced by GW_DELAYfsh and to a lower extent by RCHRGssh which shows the strong dominance of groundwater processes (see also Guse et al., 2014). However, since multiple performance criteria are influenced by GW_DELAYfsh and RCHRGssh, the most appropriate performance criterion to identify the impact of these parameter is not detectable. The second group consists of KGE_beta and RSR of mid-flow FDC segment. Both are controlled strongly by soil evaporation (ESCO) and available soil water capacity (SOL_AWC). Thirdly, low and very low flows are 
(a) KGE

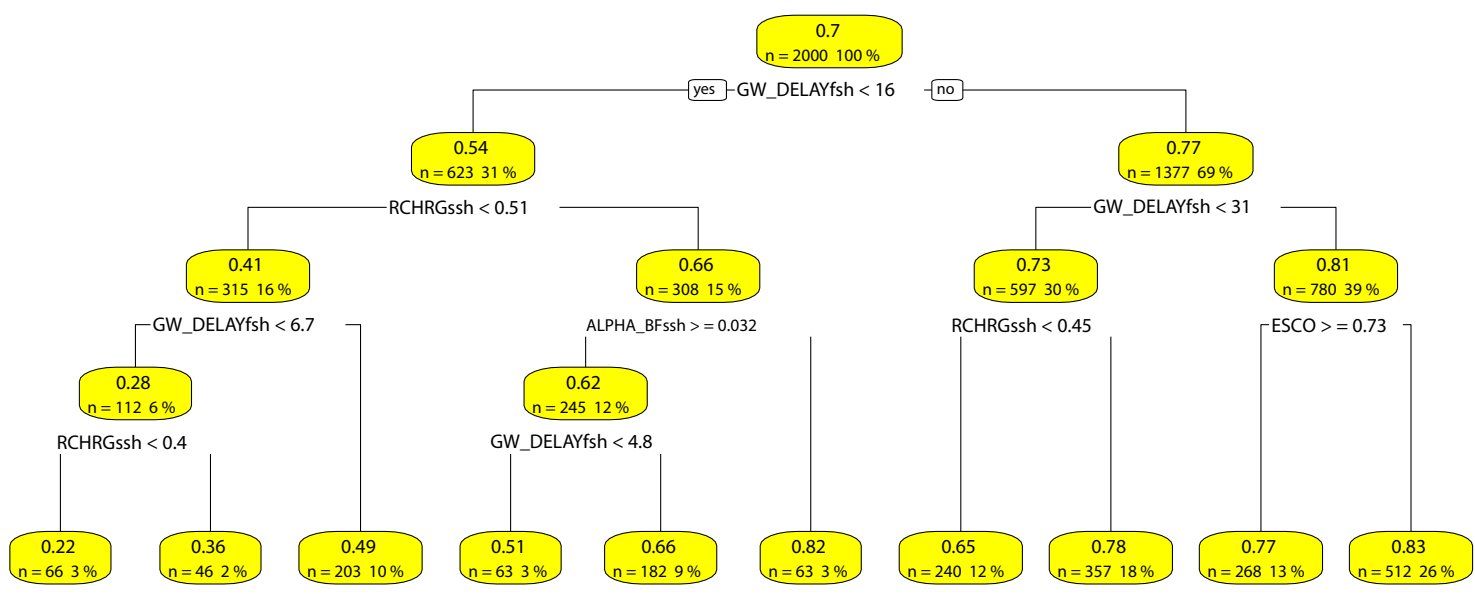

(b) GW_DELAYfsh

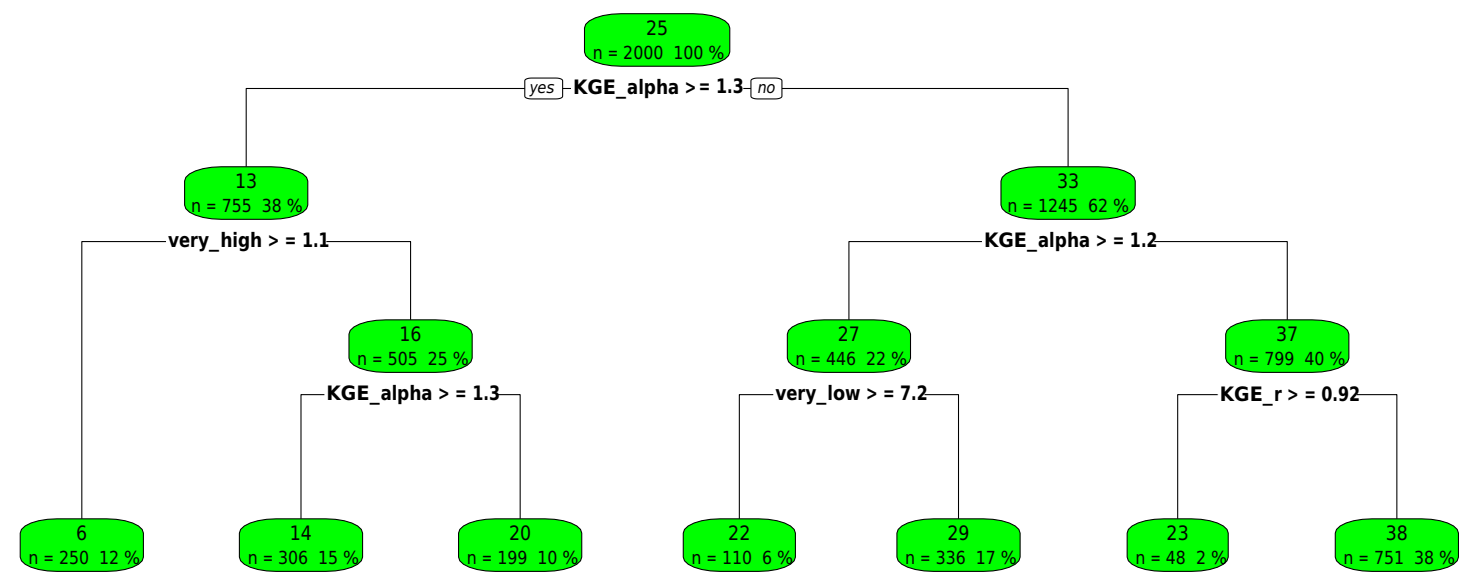

Figure 4. Example of a regression tree (RT) using (a) KGE as the target variable and model parameters as explaining variables and (b) the model parameter GW_DELAYfsh as the target variable and performance criteria as explaining variables for the Treene catchment.

controlled by the baseflow recession coefficient of the second aquifer (ALPHA_BFssh) in addition to GW_DELAYfsh. Seven of twelve model parameters, namely fast runoff $(\mathrm{CN} 2$, SURLAG, GDRAIN, LATTIME), soil (SOL_K) and snow parameters (SFTMP, SMTMP), have only a minor impact on all performance criteria and cannot be identified by the selected performance criterion.

Figure 5 shows that the relationship between model parameters and performance criteria is more complex in the Saale catchment compared to the Treene catchment. A clear classification into groups of performance criteria which are controlled by certain model parameters is more difficult. Four performance criteria (NSE, KGE_alpha, KGE_r, very highflow segment of FDC) are controlled by lateral flow lag time (LATTIME). But these performance criteria are also influenced by groundwater parameters (GW_DELAYfsh,
RCHRGssh). Furthermore, RSR for high flows is not controlled by LATTIME but by these two groundwater parameters and hydraulic conductivity in soil (SOL_K). KGE is controlled by a parameter (GW_DELAYfsh) which does not have the largest percentage contribution for one of its three components. Water balance (KGE_beta) is controlled by ESCO and SOL_AWC, while mid-flows are mainly influenced by SOL_AWC. Low flows are controlled by GW_DELAYfsh and very low flows by ALPHA_BFssh. Snow and fast runoff parameters except LATTIME do not influence any of the performance criteria to a great extent. Thus, parameters exist without significant impact and LATTIME controls multiple performance criteria in the Saale catchment as well.

When detecting the controlling model parameters for each performance criterion, in both catchments no appropriate 
(a) Treene catchment

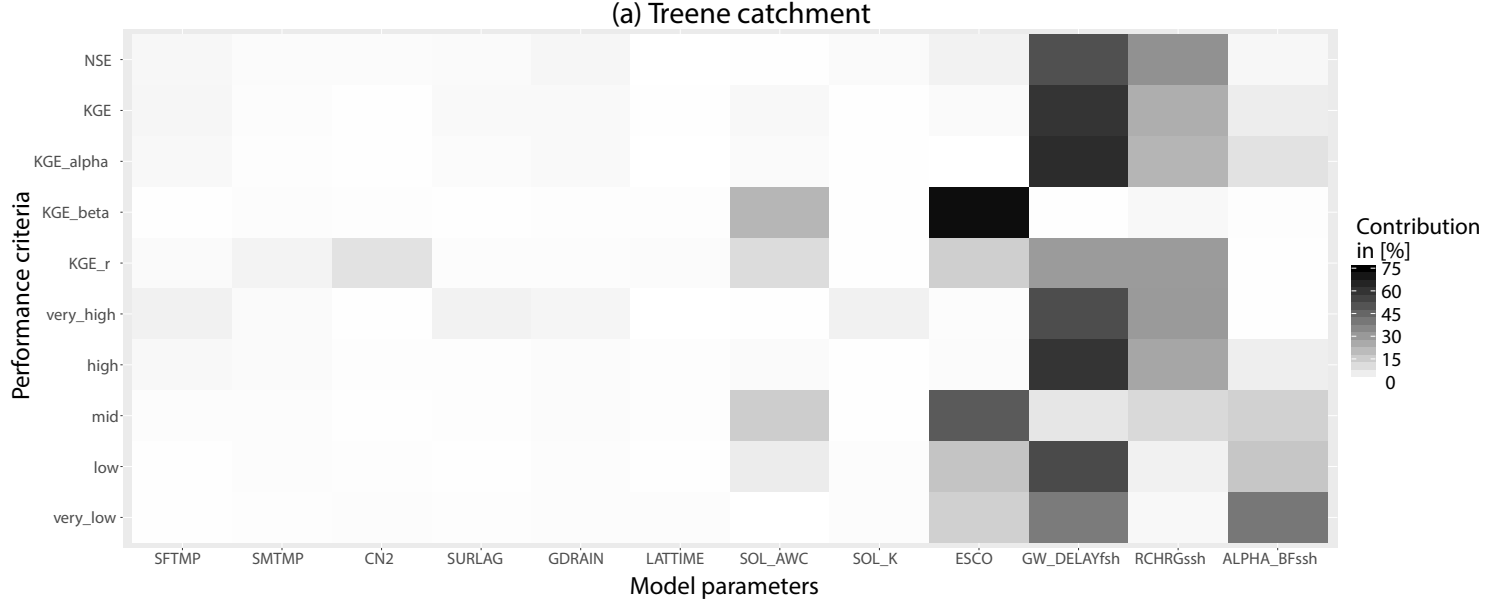

(b) Saale catchment

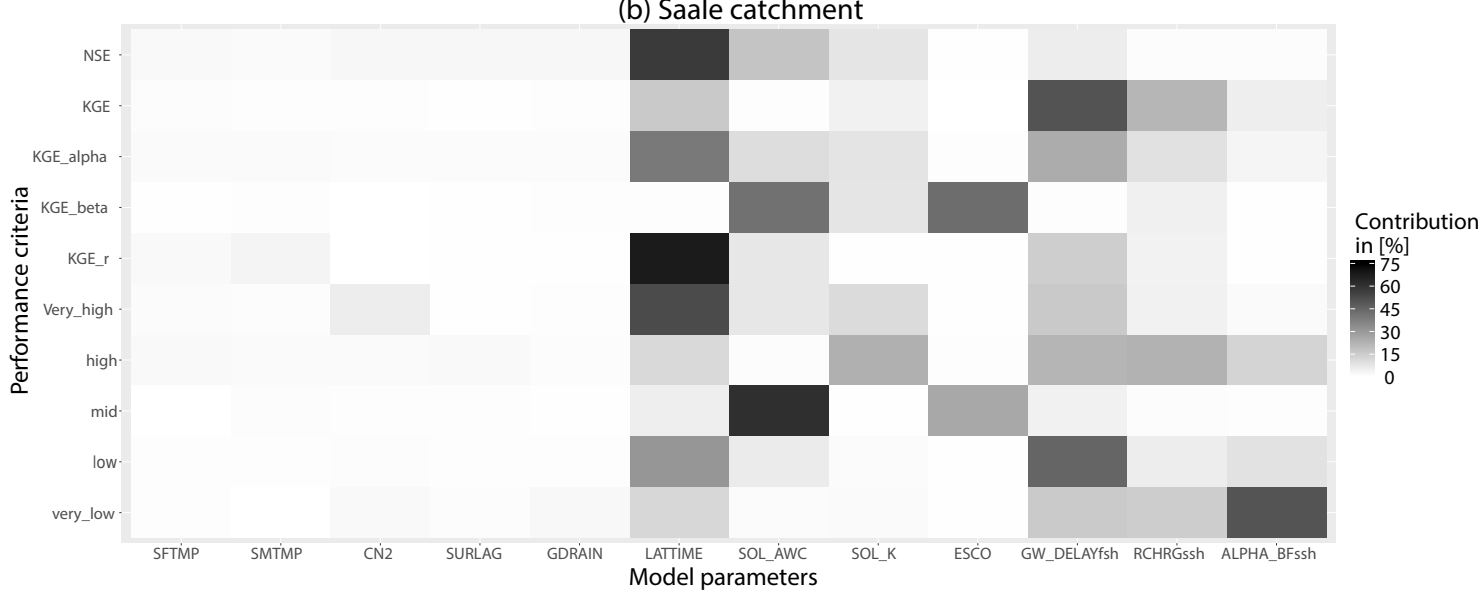

Figure 5. Regression trees (RTs) using performance criteria as target variables. The percentage contribution of model parameters in explaining performance criteria is shown for Treene (a) and Saale (b) catchment. In every row the percentage contributions sum up to $100 \%$.

performance criteria are found for several model parameters (e.g. CN2), which shows the low connective strength between these model parameters and performance criteria. This leads to more challenging identification of parameter values. It is important to detect whether the low relevance of a model parameter is related to the minor relevance of the corresponding process or whether the selected performance criterion is inappropriate to identify this model parameter. Moreover, some model parameters highly influence multiple performance criteria (e.g. GW_DELAYfsh and RCHRGssh in the Treene, LATTIME in the Saale), which leads to unclear results in the connective strength between model parameters and performance criteria. This suggests that these parameters govern the overall hydrological system in the model.

\subsection{Impact of changes in model parameters on performance criteria (RTpar)}

In the second RT application, the roles of model parameters and performance criteria are permuted. The relationship be- tween model parameters and performance criteria is analysed using 12 model parameters consecutively as target variables. It is investigated which performance criteria are impacted by changes in model parameters (RTpar, Fig. 6).

Figure 4 shows the regression tree exemplarily for the model parameter GW_DELAYfsh for the RTpar approach in the Treene catchment. Here, KGE_alpha separates the data set at the first node and occurs once at the two following branches. Moreover contrasting performance criteria are included (KGE_r, RSR for very high flows and very low flows).

In the Treene catchment (Fig. 6), curve number (CN2) is most significantly related to RSR for very high flows and furthermore to NSE, KGE and RSR for high flows. This shows that CN2 and thus surface runoff controls high-flow conditions. Snow parameters (SFTMP, SMTMP), the timing parameters for surface runoff (SURLAG) and tile flow (GDRAIN), and soil hydraulic conductivity (SOL_K) highly influence KGE_r (correlation). Thus, variations in these parameters lead to changes in correlation between measured and modelled discharge time series. Concerning the soil 


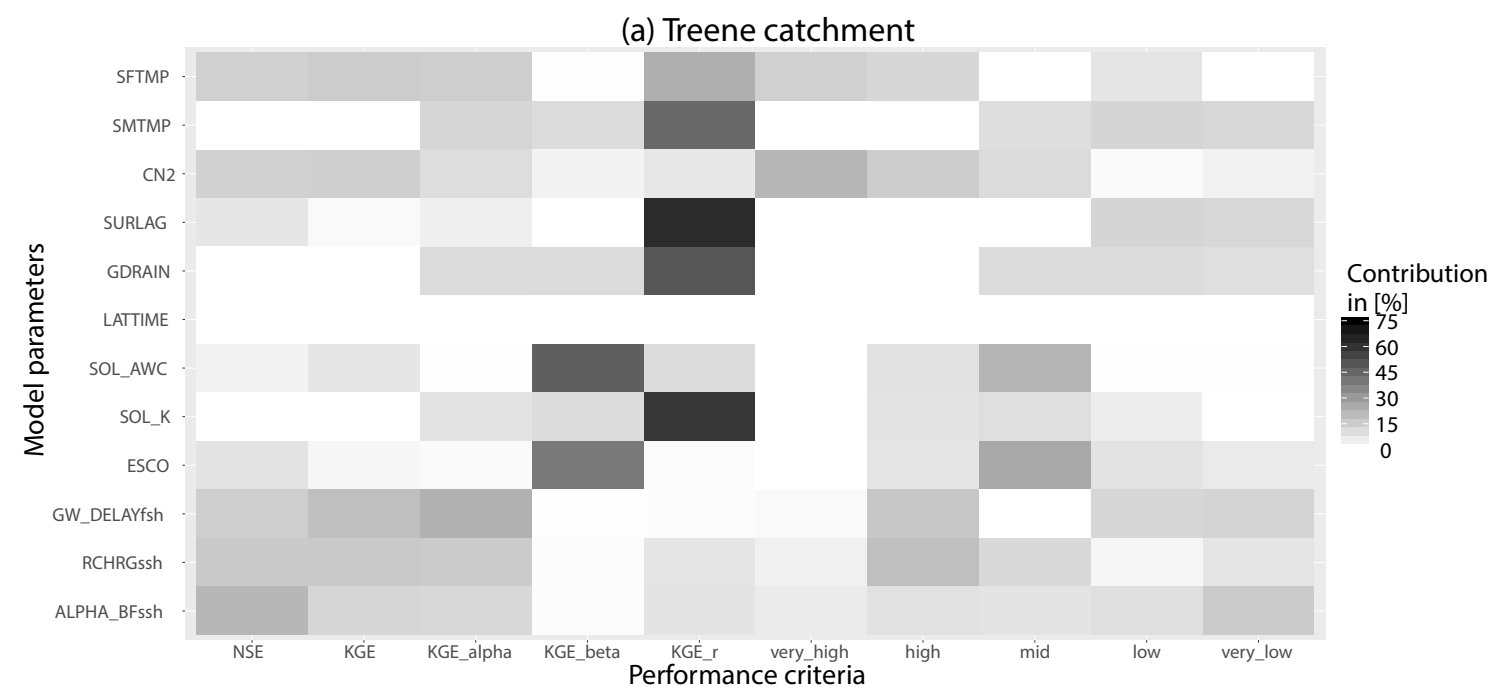

(b) Saale catchment

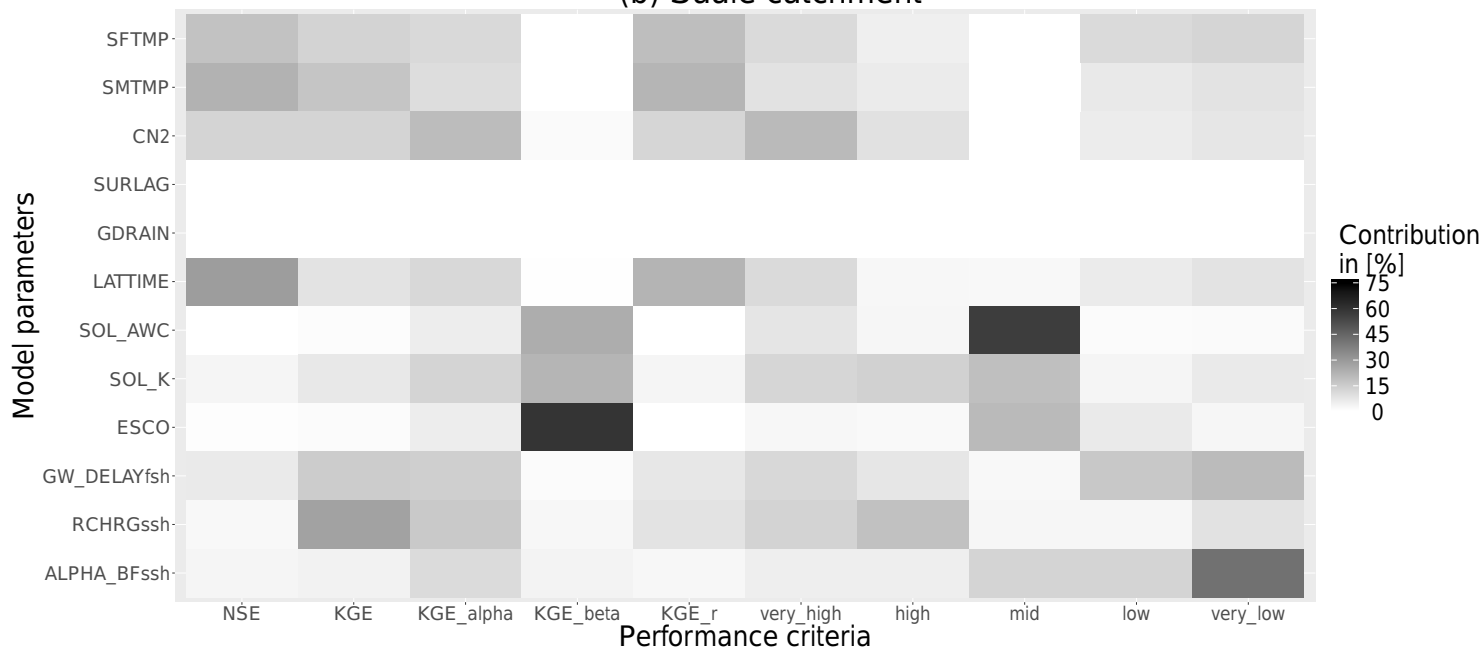

Figure 6. Regression trees (RTs) using model parameters as target variables (RTpar) for Treene (a) and Saale (b) catchment and performance criteria as explaining variables. All values of a parameter are in white in the case that the resulting variation among performance criteria for this parameter was too low to construct a regression tree. In every row the percentage contributions sum up to $100 \%$.

model component, SOL_AWC and ESCO are strongly related to water balance (KGE_beta) and to a lower extent to RSR for mid-flows. ALPHA_BFssh is related to RSR of low and very low flows as well as to NSE. For the two groundwater parameters (GW_DELAYfsh, RCHRGssh), four performance criteria (NSE, KGE, KGE_alpha, RSR for high flows) have a similar percentage contribution. This point shows that both groundwater parameters control different aspects of hydrological model behaviour without having a clear relationship with a certain part of the hydrograph.

In the Saale catchment (Fig. 6), snow parameters (SFTMP, SMTMP) and LATTIME affect both KGE_r and NSE. Changes in curve number (CN2) mainly influence KGE_alpha and RSR for very high flows. Thus, variability between measured and modelled discharge time series and in particular high flows are influenced by $\mathrm{CN} 2$. All three soil parameters (SOL_AWC, SOL_K, ESCO) influence water balance (KGE_beta) and mid-flow segment of FDC. However, evaporation (ESCO) is more related to KGE_beta while SOL_AWC has the largest impact on mid-flows. In the case of GW_DELAYfsh several performance criteria are affected to a similar extent, but none of them has a high percentage contribution. While RCHRGssh affects KGE and high flows, ALPHA_BFssh strongly controls very low flows.

\subsection{Comparing RTperf and RTpar}

Subsequently, both RT approaches are compared by relating the percentage contribution from RTperf to RTpar and analysing these patterns for each performance criterion for both catchments (Fig. 7). The joint consideration of both RTs finally yields the bijective connective strength between 

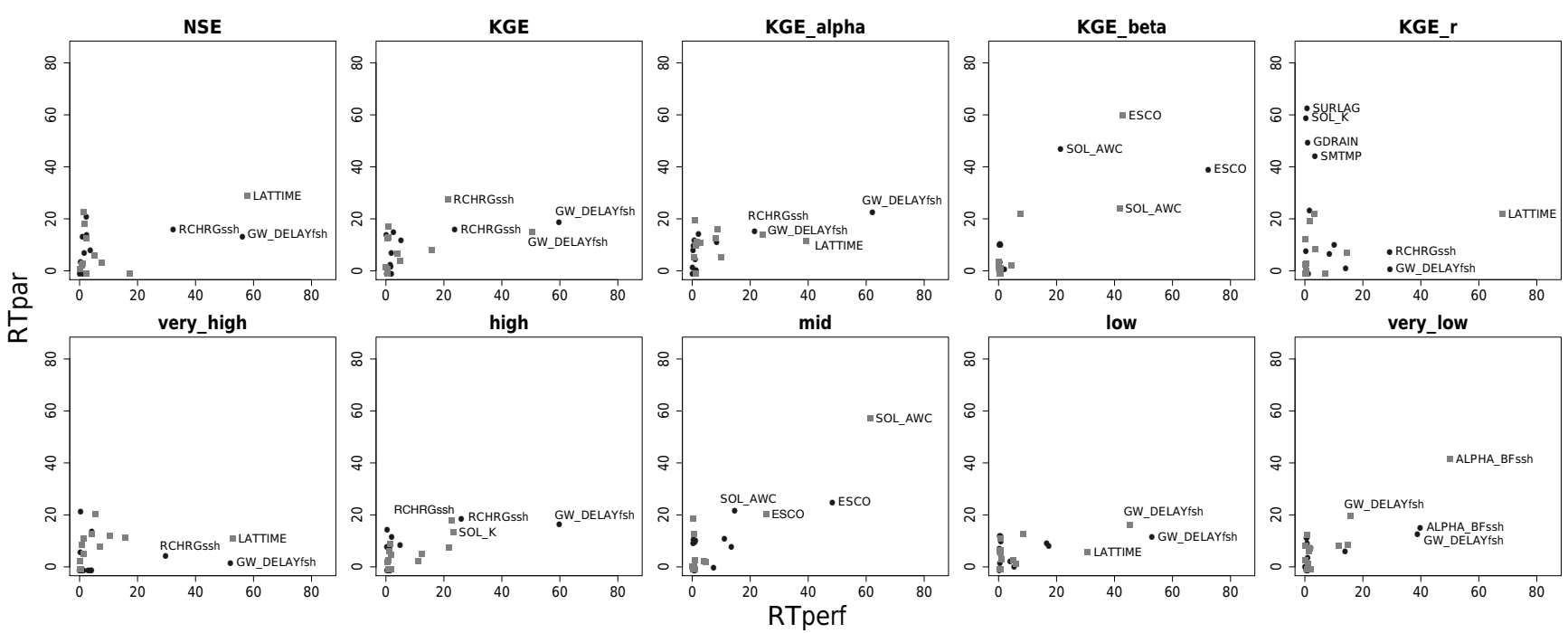

Figure 7. Connective strength between performance criteria and model parameters. The percent contribution of pairs of model parameter and performance criterion are shown as derived from RTperf ( $x$ axis) and RTpar ( $y$ axis). A high value along the $x$ axis shows a high contribution of a model parameter in explaining variability in the performance criterion as detected by RTperf. A high value along the $y$ axis (RTpar) shows that this performance criterion is most strongly impacted among all performance criteria by changes in the model parameter. Strong connective strength is detected if both values are high. The pairs with at least one high-percentage contribution are labelled. The results from Treene catchment are shown as black circles and from Saale catchment in grey squares. Please note that percentage contributions on the $x$ axis sum up to $100 \%$, while this is not the case for the $y$ axis.

model parameter and performance criteria. A high connective strength between a distinct model parameter and a distinct performance criterion is given if (1) the model parameter is one of the dominant controls for the performance criterion and (2) the same performance criterion is sensitive to changes in the model parameter values to a relevant extent.

For mid-and low-flow conditions, both RTperf and RTpar provide strong connective strength with high percentage contribution in RTperf and RTpar for the same pair of model parameter and performance criterion in both catchments. The strong relationship of evaporation (ESCO) and available soil water capacity (SOL_AWC) to RSR of mid-flows and KGE_beta is derived in both RT approaches (Fig. 7). Water balance (KGE_beta) is hereby more controlled by ESCO, whilst SOL_AWC is the dominant parameter for mid-flows especially in the Saale catchment.

Similarly, the connection between RSR for the very low segment of FDC and the baseflow recession coefficient (ALPHA_BFssh) is strong particularly in the Saale catchment. In both catchments the retention time of recharge into groundwater (GW_DELAYfsh) is also relevant.

KGE is dominated by GW_DELAYfsh and the aquifer partitioning coefficient (RCHRGssh) in a similar way in both catchments despite contrasting catchment characteristics. In RTperf, KGE is most strongly impacted by GW_DELAYfsh. However, in RTpar, KGE has a higher percentage contribution in explaining changes in RCHRGssh than in GW_DELAYfsh.
In contrast, performance criteria related to high flows (NSE and RSR for very high flows) are controlled in the Treene catchment by groundwater (GW_DELAYfsh, RCHRGssh) and in the Saale catchment by lateral flow (LATTIME). This pattern shows that NSE focuses on model errors at high flows. A lower connective strength between model parameters and performance criteria was detected for highflow conditions. A bijective relationship between high-flowrelated performance criteria and certain model parameters is more difficult to detect. The five performance criteria representing high-flow conditions in the Treene catchment are related to the same two groundwater parameters (GWDELAYfsh and RCHRGssh). However, whilst GWDELAYfsh and RCHRGssh are the most dominant model parameters in RTperf, the percentage contribution in RTpar is lower. These two parameters dominate five performance criteria, but it remains unclear which is the best performance criterion in terms of parameter identification. Thus, while model errors in mid- and low flows are identified in both catchments by the same performance criteria (case 1; see Sect. 2.4.3), it is more complex to find appropriate performance criteria for errors in high flows. Here, more complex hydrological behaviour is detected, particularly in the Saale catchment, as indicated by different controlling parameters on the performance criterion (case 2 and 3 in Sect. 2.4.3). Moreover, the most dominant parameters in both catchments (GW_DELAYfsh in the Treene, LATTIME in the Saale) have a high percentage contribution in particular in RTperf both for high and low flows. 
A very specific pattern is detected for KGE_r in the Treene catchment. In RTpar, a high percentage contribution of KGE_r for model parameters of lower relevance is detected. High values for RTpar and low values for RTperf in Fig. 7 show that KGE_r is the most appropriate performance criterion to assess changes in these model parameters. However, due to low relevance of snow or surface runoff, KGE_r is controlled by groundwater parameters. Here, we see a large difference in the interrelationship between model parameters and performance criteria by comparing RTperf and RTpar.

\section{Discussion}

The aim of this study was to improve the understanding of the relationship between model parameters and performance criteria. To this end, the concept of connective strength between model parameters and performance criteria was introduced, based on two approaches of regression trees first using performance criteria and then model parameters as target variables. Based on this, we discuss how the connective strength to the performance criteria varies between different model parameters and how the use of different performance criteria help in identifying model parameters.

\subsection{Benefit of analysing bijectively the relationship between model parameters and performance criteria}

By analysing the connective strength, the performance criteria which are appropriate to best constrain the model parameters are identified. The novelty of this study lies in the assessment of the relationship between model parameters and performance criteria bijectively (RTperf, RTpar).

In RTperf, detection for 10 performance criteria is performed to ascertain whether the same model parameters affect different performance criteria. It is shown that not all model parameters influence one of the selected performance criteria (see Fig. 5). This indicates that not all model parameters can be identified with this approach since either the model parameters are not relevant or appropriate performance criteria are still missing to describe the changes in this model parameter. The impact of model parameters on performance criteria depends on the relevance of the corresponding process. In the case that the relevance of the associated process is very low, parameters from other more dominant processes control performance criteria. This is for example shown for curve number (CN2). Its impact on performance criteria in Treene catchment is low due to higher contribution of groundwater flow compared to surface runoff.

In RTpar with model parameters as target variables, each model parameter is individually assessed. By comparing RTpar for different model parameters, the influence of model parameters on different performance criteria is identified. It can be derived whether parameters and their associated pro- cesses are of low relevance or whether an appropriate performance criterion for a model parameter is missing. The RTpar approach shows for the majority of the model parameters that changes in their values are detectable at least by one selected performance criteria. This indicates that the impact of model parameters related to processes of minor relevance on performance criteria can be derived with RTpar.

Differences between RTperf and RTpar are also obtained for parameters related to the most dominant process(es). The groundwater parameters (mainly GW_DELAYfsh) control most of performance criteria for the Treene catchment (Fig. 5). A similar result is obtained for the Saale catchment with a dominance of lateral flow lag time (LATTIME). Comparing results of two RT approaches, a higher similarity between both catchments is detected in RTpar (Fig. 6).

Comparing the results of both RT approaches (Figs. 5 and 6 ), it becomes apparent that the performance criterion with the highest percent contribution for a given model parameter in Fig. 5 is in some cases not identical with the performance criterion with highest percent contribution in Fig. 6. Thus, the analysis from the side of the model parameters provides additional information about the interrelationship between model parameters and performance criteria.

The interpretation of the relationship between model parameters and performance criteria from both sites by means of the suggested connective strength extends the classical one-sided analysis of the impact of model parameters on performance criteria as in, for example, sensitivity analyses (van Werkhoven et al., 2008; Herman et al., 2013). In our approach both performance criteria and model parameters were analysed separately as target variables. In comparison to the established one-sided approaches, this yields additional information on which performance criteria are appropriate for a certain model parameter.

Thus, we investigate not only how variations are propagated in the model up to the output but also which outputs (i.e. performance criteria) are impacted by a certain model parameter. The comparison of parameter relevance with former studies on temporally resolved parameter sensitivity analyses (Guse et al., 2014, 2016) shows that the overall ranking of model parameters is similar.

\subsection{Benefit of using different performance criteria}

Furthermore, we analysed how the use of different performance criteria helps in identifying model parameters. The differences in the relevance of model parameters on 10 performance criteria emphasised the benefit of using this set of performance criteria. The separate consideration of KGE components demonstrates that different parameters are related to these three performance metrics of KGE. While relevant parameters on KGE and KGE_alpha are similar in the Treene catchment, the most relevant parameter on KGE in the Saale catchment (GW_DELAY) is not the relevant one for the three KGE components. Since each KGE component 
can be clearly related to a specific part of hydrological behaviour (Kling et al., 2012), the RT shows whether a model parameter is more relevant in representing variability, bias or correlation in modelled discharge time series. By comparing the performance in KGE with its components, the most important aspect in evaluating the model performance with KGE becomes apparent. For example, in the Treene catchment variability is the most important one, as indicated by KGE_alpha.

The differences in pairwise correlations of performance criteria between both catchments also result in differences in the relationship between model parameters and a certain performance criterion. Similar results in KGE and NSE are calculated in the case of high correlation between KGE and KGE_alpha and thus the most relevant model parameters on these two performance criteria are similar. The opposite result is obtained in the Saale catchment. Due to low values of KGE_alpha, different parameters control KGE and NSE. This pattern is reasonable since both KGE_alpha and NSE focus on assessment of variability in discharge time series, while the three components (variability, bias, correlation) are equally weighted in KGE.

Concerning signature measures, this study shows that different parameters are related to FDC segments. This is in line with studies stating that each FDC segment can be related to certain catchment processes (Yilmaz et al., 2008; Yaeger et al., 2012; Pfannerstill et al., 2015). The strong connective strength of model parameters regulating water balance to mid-flows as well as of parameters from slow reacting aquifer storages to very low flows is derived in this study. However, a typical sequence of a high connective strength of high flows to surface runoff parameters is not identified. Moreover, we observe that dominant processes, i.e. groundwater flow in the Treene and lateral flow in the Saale catchment, influence both high and low flows. This leads to a trade-off in parameter identification since the same model parameters control high and low flows. This shows that performance criteria should be specific for different model parameters, in this case specific for either high or low flow, to avoid a high parameter uncertainty and equifinality in the estimation of behavioural parameter sets.

\subsection{Number of required performance criteria}

The analysis of the bijective connective strength between pairs of model parameters and performance criteria in the two catchments shows that the most appropriate performance criterion varies depending on different model parameters. Pairs with a high connective strength were detected and grouped. This results in a minimum number of three required performance criteria related to high-, mid- and lowflow conditions since the most relevant parameters between these three types of performance criteria vary. This is in line with other studies on performance criteria stating that three or four performance criteria are needed at a minimum to cap- turing different parts of the hydrological system (Madsen, 2000; Boyle et al., 2001; van Werkhoven et al., 2008, 2009).

In addition, an individual performance criterion for a single model parameter might be needed, e.g. to assess the importance of mid-flows (van Werkhoven et al., 2008; Wagener et al., 2009; Herman et al., 2013). This is shown in the RT analysis, where the controlling parameters for KGE_beta and RSR for mid-flows are different compared to other performance criteria and these dominant model parameters are from soil components and related to water balance. In these cases, the connective strength is very high.

In addition, for the assessment of low-flow conditions, an individual performance criterion is needed which was in this case RSR for low and very low flows. A high connective strength between model parameter and performance criterion was detected for very low flows. Moreover, the requirement for a segmentation of FDC into very low and low flows as introduced by Pfannerstill et al. (2014b) is emphasised by identifying different relevant model parameters. The high correlation between RSR for very low and low flows in the Treene catchment also results in similar dominant parameters, while different parameters control these signature measures in the Saale catchment (see Fig. 5). Thus, similar influencing parameters in RTperf for different performance criteria are detected if both are highly correlated.

High flows are driven by interacting and overlaying processes from different hydrological components. Here, the most influential parameters and the most appropriate performance criterion vary depending on the type of errors which are dominant in the modelling process. The complexity in the representation of high flows depends on the involved processes. In the groundwater-dominated Treene catchment, the RT analysis for five performance criteria related to high flows provides very similar results. The RT analysis using model parameters as explaining variables (RTpar) however highlights differences in the relationship of model parameters and these five performance criteria. In the Saale catchment, relevant model parameters largely vary between all performance criteria related to high flows. Here, all selected performance criteria capture different types of errors in modelled discharge time series. The analysis of deviations between measured and modelled discharge in this catchment is more complex so that more than one performance criterion for high flows is required. With higher heterogeneity in dominant processes and strong interaction of different processes in controlling hydrological behaviour, a more distinct selection of a larger set of performance measures is required.

Thus, we recommend including several performance criteria to capture all types of potential errors both in the dynamic and magnitude of modelled discharge. In addition, it is relevant to consider which model parameters dominate performance criteria. This can help to understand why a certain model error might occur and to which processes this model error is related. 
As demonstrated in this study, the results vary between different catchments. Further studies in other catchments might additionally improve the understanding of the connective strength between model parameters and performance criteria using this methodology. A separate approach for specific time periods, for example, in winter to capture the impact of snow parameters, might be an upcoming interest. Due to the generality of the suggested approach, applicability with other models is expected.

\section{Conclusion}

For achieving precise parameter identification, the connective strength between model parameters and different performance criteria is analysed. For this, two regression tree (RT) approaches are applied using consecutively performance criteria and model parameters as target variables. This method derives which model parameters affect a performance criterion (RTperf) and which performance criteria are impacted by changes in model parameters (RTpar). By detecting the connective strength between model parameters and performance criteria, appropriate performance criteria can be derived for different model parameters. Based on precise parameter identification and a better understanding of model parameters, parameter uncertainty and thus equifinality among different model runs can be reduced.

Thus, the main outcomes of this study are as follows:

1. The pairwise correlation between performance criteria varies between the two catchments depending on the model error. Thus, different performance criteria are required to disentangle the impact of different hydrological behaviour on modelled discharge. The number of required performance criteria is higher for catchments with a higher process complexity.

2. In RTperf, it becomes apparent how largely the relevance of model parameters varies between different performance criteria. Our study emphasises the importance of a separate consideration of KGE components and of a signature-based analysis of different FDC segments for precise parameter identification. Differences in dominant parameters are detected between performance criteria related to high-, mid- or low-flow conditions.

3. RTpar, which uses model parameters as target variables, shows which performance criterion is appropriate to identify a model parameter. Similar results in RTperf and RTpar demonstrate high capability of a performance criterion to consider the impact of a model parameter accurately. Contrasting results are in particular derived for model parameters which are related to processes of minor relevance. A bijective connective strength between model parameters and performance criteria is detected for low and mid-flows, whilst modelling of high flows is more complex both in terms of relevant model parameters and appropriate performance criteria.

Overall, this study shows that multiple performance criteria are required for accurate parameter identification for reliable hydrological modelling. However, no general conclusion regarding universal performance criteria can be drawn, since the connective strength between model parameters and performance criteria varies between catchments depending on hydrological complexity of the catchments with respect to processes and their relevance in controlling hydrological behaviour in models. Using the presented approach, one can derive how precisely reasonable values of model parameters can be identified by a set of performance criteria.

Data availability. We are not permitted to distribute all data of the hydrological model. The results of the model simulations can be provided upon request by contacting the first author.

Competing interests. The authors declare that they have no conflict of interest.

Acknowledgements. We thank the DFG for financially supporting the first author (BG; project GU 1466/1-1 Hydrological consistency in modelling). Furthermore we thank the CAWa (Central Asian Water) project (www.cawa-project.net, contract no. AA7090002) of the German Federal Foreign Office as part of the German Water Initiative for Central Asia (Berlin Process) for the funding of the third author (AG). The fourth author (JK) was funded through the GLANCE project (Global change effects in river ecosystems; 01LN1320A) supported by the German Federal Ministry of Education and Research (BMBF). The fifth author (CL) received funding from the Leibniz Association (SAW-2012-IGB-4167) within the International Leibniz Research School: Aquatic boundaries and linkages in a changing environment (Aqualink).

We thank the Agency for Coastal Defence, National Park and Marine Conservation of Schleswig-Holstein (LKN-SH) and the State Institute for Environment and Geology of Thuringia (TLUG) for the discharge data. We thank Martin Volk and Michael Strauch (UFZ) for contributing to the SWAT modelling in the Saale catchment. Furthermore, we thank the community of the open-source software R, which we used for this study.

Edited by: Dimitri Solomatine

Reviewed by: Richard Arsenault and two anonymous referees 


\section{References}

Abebe, N. A., Ogden, F. L., and Pradhan, N. R.: Sensitivity and uncertainty analysis of the conceptual HBV rainfall-runoff model: Implications for parameter estimation, J. Hydrol., 389, 301-310, 2010.

Arnold, J. G., Srinivasan, R., Muttiah, R. S., and Williams, J. R.: Large area hydrologic modeling and assessment part I: model development, J. Am. Water Resour. As., 34, 73-89, 1998.

Atkinson, S. E., Woods, R. A., and Sivapalan, M.: Climate and landscape controls on water balance model complexity over changing timescales, Water Resour. Res., 38, 1314, https://doi.org/10.1029/2002WR001487, 2002.

Boyle, D. P., Gupta, H. V., Sorooshian, S., Koren, V., Zhang, Z., and Smith, M.: Toward improved streamflow forecasts: Value of semidistributed modeling, Water Resour. Res., 37, 2749-2759, 2001.

Breiman, L., Friedman, J. H., Olshen, R. A., and Stone, C. J.: Classification and Regression Trees, CRC Press, Wadsworth, Belmont, CA, 1984.

Cheng, L., Yaeger, M., Viglione, A., Coopersmith, E., Ye, S., and Sivapalan, M.: Exploring the physical controls of regional patterns of flow duration curves - Part 1: Insights from statistical analyses, Hydrol. Earth Syst. Sci., 16, 4435-4446, https://doi.org/10.5194/hess-16-4435-2012, 2012.

Euser, T., Winsemius, H. C., Hrachowitz, M., Fenicia, F., Uhlenbrook, S., and Savenije, H. H. G.: A framework to assess the realism of model structures using hydrological signatures, Hydrol. Earth Syst. Sci., 17, 1893-1912, https://doi.org/10.5194/hess-171893-2013, 2013.

Fenicia, F., Savenije, H. H., Matgen, P., and Pfister, L.: A comparison of alternative multiobjective calibration strategies for hydrological modeling, Water Resour. Res., 43, W03434, https://doi.org/10.1029/2006WR005098, 2007.

Gupta, H. V., Wagener, T., and Liu, Y.: Reconciling theory with observations: Elements of a diagnostic approach to model evaluation, Hydrol. Process., 22, 3802-3813, 2008.

Gupta, H. V., Kling, H., Yilmaz, K. K., and Martinez, G. F.: Decomposition of the mean squared error and NSE performance criteria: Implications for improving hydrological modelling, J. Hydrol., 377, 80-91, 2009.

Gupta, H. V., Sorooshian, S., and Yapo, P. O.: Toward improved calibration of hydrologic models: Combining the strengths of manual and automatic methods, Water Resour. Res., 34, 751-763, 1998.

Gupta, H. V., Perrin, C., Blöschl, G., Montanari, A., Kumar, R., Clark, M., and Andréassian, V.: Large-sample hydrology: a need to balance depth with breadth, Hydrol. Earth Syst. Sci., 18, 463477, https://doi.org/10.5194/hess-18-463-2014, 2014.

Guse, B., Reusser, D. E., and Fohrer, N.: How to improve the representation of hydrological processes in SWAT for a lowland catchment - temporal analysis of parameter sensitivity and model performance, Hydrol. Process., 28, 2651-2670, https://doi.org/10.1002/hyp.9777, 2014.

Guse, B., Pfannerstill, M., and Fohrer, N.: Dynamic modelling of land use change impacts on nitrate loads in rivers, Environ. Process., 2, 575-592, https://doi.org/10.1007/s40710-015-0099$\mathrm{x}, 2015$.

Guse, B., Pfannerstill, M., Strauch, M., Reusser, D. E., Volk, M., Gupta, H. V., and Fohrer, N.: On characterizing the temporal dominance patterns of model parameters and processes, Hydrol. Process., 30, 2255-2270, https://doi.org/10.1002/hyp.10764, 2016.

Haas, M. B., Guse, B., Pfannerstill, M., and Fohrer, N.: A joined multi-metric calibration of river discharge and nitrate loads with different performance measures, J. Hydrol., 536, 534-545, https://doi.org/10.1016/j.jhydrol.2016.03.001, 2016.

Herman, J. D., Reed, P. M., and Wagener, T.: Time-varying sensitivity analysis clarifies the effects of watershed model formulation on model behavior, Water Resour. Res., 49, 1400-1414, https://doi.org/10.1002/wrcr.20124, 2013.

Jarvis, A., Reuter, H. I., Nelson, A., and Guevara, E.: Hole-filled SRTM for the globe Version 4, available from the CGIARCSI SRTM 90 m Database, http://srtm.csi.cgiar.org (last access: 31 January 2013), 2008.

Jothityangkoon, C. and Sivapalan, M.: Framework for exploration of climatic and landscape controls on catchment water balance, with emphasis on inter-annual variability, J. Hydrol., 371, 154168, 2009.

Kiesel, J., Fohrer, N., Schmalz, B., and White, M. J.: Incorporating landscape depressions and tile drainages of lowland catchments into spatially distributed hydrologic modeling, Hydrol. Process., 24, 1472-1486, 2010.

Kling, H., Fuchs, M., and Paulin, M.: Runoff conditions in the Upper Danube basin under an ensemble of climate change scenarios, J. Hydrol., 424-425, 264-277, 2012.

Krause, P., Boyle, D. P., and Bäse, F.: Comparison of different efficiency criteria for hydrological model assessment, Adv. Geosci., 5, 89-97, https://doi.org/10.5194/adgeo-5-89-2005, 2005.

Madsen, H.: Automatic calibration of a conceptual rainfall-runoff model using multiple objectives, J. Hydrol., 235, 276-288, 2000.

Madsen, H., Wilson, G., and Ammentorp, H. C.: Comparison of different automated strategies for calibration of rainfall-runoff models, J. Hydrol., 261, 48-59, 2002.

Martinez, G. F. and Gupta, H. V.: Toward improved identification of hydrological models: A diagnostic evaluation of the "abcd" monthly water balance model for the conterminous United States. Water Resour. Res., 46, W08507, https://doi.org/10.1029/2009WR008294, 2010.

Martinez, G. F. and Gupta, H. V.: Hydrologic consistency as a basis for assessing complexity of monthly water balance models for the continental United States, Water Resour. Res., 47, W12540, https://doi.org/10.1029/2011WR011229, 2011.

Merz, R. and Blöschl, G.: Regionalisation of catchment model parameters, J. Hydrol., 287, 95-123, 2004.

Moriasi, D. N., Arnold, J. R., Van Liew, M. W., Bingner, R. L., Harmel, R. D., and Veith, T. L.: Model evaluation guidelines for systematic quantification of accuracy in watershed simulations, T. ASABE, 50, 885-900, 2007.

Nash, J. E. and Sutcliffe, J. V.: River flow forecasting through conceptual models: part i-a discussion of principles, J. Hydrol., 10, 282-290, 1970.

Neitsch, S. L., Arnold, J. G., Kiniry, J. R., and Williams, J. R.: Soil and Water Assessment Tool - Theoretical documentation version 2009, Texas Water Resources Institute Technical Report, 406, 2011.

Pechlivanidis, I. G. and Arheimer, B.: Large-scale hydrological modelling by using modified PUB recommendations: the 
India-HYPE case, Hydrol. Earth Syst. Sci., 19, 4559-4579, https://doi.org/10.5194/hess-19-4559-2015, 2015.

Pechlivanidis, I. G., Jackson, B., McMillan, H., and Gupta, H.: Use of entropy-based metric in multiobjective calibration to improve model performance, Water Resour. Res., 50, 8066-8083, https://doi.org/10.1002/2013WR014537, 2014.

Pfannerstill, M., Guse, B., and Fohrer, N.: A multi-storage groundwater concept for the swat model to emphasize nonlinear groundwater dynamics in lowland catchments, Hydrol. Process., 28, 5599-5612, https://doi.org/10.1002/hyp.10062, 2014a.

Pfannerstill, M., Guse, B., and Fohrer, N.: Smart low flow signature metrics for an improved overall performance evaluation of hydrological models, J. Hydrol., 510, 447-458, https://doi.org/10.1016/j.jhydrol.2013.12.044, 2014b.

Pfannerstill, M., Guse, B., Reusser, D., and Fohrer, N.: Process verification of a hydrological model using a temporal parameter sensitivity analysis, Hydrol. Earth Syst. Sci., 19, 4365-4376, https://doi.org/10.5194/hess-19-4365-2015, 2015.

Pokhrel, P., Yilmaz, K. K., and Gupta, H. V.: Multiple-criteria calibration of a distributed watershed model using spatial regularization and response signatures, J. Hydrol., 418-419, 49-60, 2012.

Reusser, D. E., Blume, T., Schaefli, B., and Zehe, E.: Analysing the temporal dynamics of model performance for hydrological models, Hydrol. Earth Syst. Sci., 13, 999-1018, https://doi.org/10.5194/hess-13-999-2009, 2009.

Reusser, D. E., Buytaert, W., and Zehe, E.: Temporal dynamics of model parameter sensitivity for computationally expensive models with FAST (Fourier Amplitude Sensitivity Test), Water Resour. Res., 47, W07551, https://doi.org/10.1029/2010WR009947, 2011.

Schaefli, B. and Gupta, H. V.: Do Nash values have value?, Hydrol. Process., 21, 2075-2080, 2007.

SCS: Section 4 Hydrology in National Engineering Handbook, Soil Conservation Service, 1972.

Singh, R., Wagener, T., van Werkhoven, K., Mann, M. E., and Crane, R.: A trading-space-for-time approach to probabilistic continuous streamflow predictions in a changing climate - accounting for changing watershed behavior, Hydrol. Earth Syst. Sci., 15, 3591-3603, https://doi.org/10.5194/hess-15-3591-2011, 2011.

Singh, R., Archfield, S. A., and Wagener, T.: Identifying dominant controls on hydrologic parameter transfer from gauged to ungauged catchments - a comparative hydrology approach, J. Hydrol., 517, 985-996, 2014a.

Singh, R., Wagener, T., Crane, R., Mann, M. E., and Ning, L.: A vulnerability driven approach to identify adverse climate and land use change combination for critical hydrologic indicator thresholds: Application to a watershed in Pennsylvania, USA, Water Resour. Res., 50, 3409-3427, https://doi.org/10.1002/2013WR014988, 2014b.

Soetaert, K. and Petzoldt, T.: Inverse modelling, senstivity and monte carlo analysis in $\mathrm{r}$ using package FME, J. Stat. Softw., 33, 1-28, https://doi.org/10.18637/jss.v033.i03, 2010.

Therneau, T. M., Atkinson, B., and Ripley, B.: Rpart: Recursive partitioning, $\mathrm{R}$ package, version 4.1-10, available at: http://CRAN. R-project.org/package=rpart (last access: 24 October 2015), 2015. van Werkhoven, K., Wagener, T., Reed, P., and Tang, Y.: Rainfall characteristics define the value of streamflow observations for distributed watershed model identification, Geophys. Res. Lett., 35, L11403, https://doi.org/10.1029/2008GL034162, 2008.

van Werkhoven, K., Wagener, T., Reed, P., and Tang, Y.: Sensitivity-guided reduction of parametric dimensionality for multi-objective calibration of watershed models, Adv. Water Resour., 32, 1154-1169, https://doi.org/10.1016/j.advwatres.2009.03.002, 2009.

Vogel, R. M. and Fennessey, N. M.: Flow-duration curves II: A review of applications in water resources planning, Water Resour. Bull., 31, 1029-1039, 1996.

Vrugt, J., Gupta, H. V., Bastidas, L. A., Bouten, W., and Sorooshian, S.: Effective and efficient algorithm for multiobjective optimization of hydrological models, Water Resour. Res., 39, 1214-1232, 2003.

Wagener, T. and Montanari, A.: Convergence of approaches toward reducing uncertainty in predictions in ungauged basins, Water Resour. Res., 47, W06301, https://doi.org/10.1029/2010WR009469, 2011.

Wagener, T., Boyle, D. P., Lees, M. J., Wheater, H. S., Gupta, H. V., and Sorooshian, S.: A framework for development and application of hydrological models, Hydrol. Earth Syst. Sci., 5, 13-26, https://doi.org/10.5194/hess-5-13-2001, 2001.

Wagener, T., McIntyre, N., Lees, M. J., Wheater, H. S., and Gupta, H. V.: Towards reduced uncertainty in conceptual rainfall-runoff modelling: Dynamic identifiability analysis, Hydrol. Process., 17, 455-476, 2003.

Wagener, T., van Werkhoven, K., Reed, P., and Tang, Y.: Multiobjective sensitivity analysis to understand the information content in streamflow observations for distributed watershed modeling, Water Resour. Res., 45, W02501, https://doi.org/10.1029/2008WR007347, 2009.

Westerberg, I. K., Guerrero, J.-L., Younger, P. M., Beven, K. J., Seibert, J., Halldin, S., Freer, J. E., and Xu, C.-Y.: Calibration of hydrological models using flow-duration curves, Hydrol. Earth Syst. Sci., 15, 2205-2227, https://doi.org/10.5194/hess-15-22052011, 2011.

Yaeger, M., Coopersmith, E., Ye, S., Cheng, L., Viglione, A., and Sivapalan, M.: Exploring the physical controls of regional patterns of flow duration curves - Part 4: A synthesis of empirical analysis, process modeling and catchment classification, Hydrol. Earth Syst. Sci., 16, 4483-4498, https://doi.org/10.5194/hess-164483-2012, 2012.

Yapo, P. O., Gupta, H. V., and Sorooshian, S.: Multi-objective global optimization for hydrologic models, J. Hydrol., 204, 8397, 1998.

Yilmaz, K. K., Gupta, H. V., and Wagener, T.: A process-based diagnostic approach to model evaluation: Application to the NWS distributed hydrologic model, Water Resour. Res., 44, W09417, https://doi.org/10.1029/2007WR006716, 2008. 